\title{
Influence of the Heating Rate on the Foaming Behavior of Various Aluminium Alloys
}

\author{
Tillmann R. Neu ${ }^{1,2, *(1)}$, Beate Pfretzschner ${ }^{1}$, Francisco García-Moreno ${ }^{1,2}$ and John Banhart ${ }^{1,2}$ \\ 1 Chair of Structure and Properties of Materials, Technische Universität Berlin, Hardenbergstraße 36, \\ 10623 Berlin, Germany; beate.pfretzschner@bam.de (B.P.); garcia-moreno@helmholtz-berlin.de (F.G.-M.); \\ banhart@helmholtz-berlin.de (J.B.) \\ 2 Institute of Applied Materials, Helmholtz-Centre Berlin for Materials and Energy $\mathrm{GmbH}$, \\ Hahn-Meitner-Platz 1, 14109 Berlin, Germany \\ * Correspondence: tillmann.neu@helmholtz-berlin.de; Tel.: +49-30-3142-9229
}

Received: 14 July 2017; Accepted: 11 August 2017; Published: 23 August 2017

\begin{abstract}
Powders of metallurgically prepared precursors expand to a foam differently depending on how fast they are heated to their foaming temperature. The foaming behavior of four alloys was studied with heating rates varying from $0.1 \mathrm{~K} / \mathrm{s}$ to $18 \mathrm{~K} / \mathrm{s}$. It was found that each alloy shows its own non-linear behavior of expansion values. Alloys not containing magnesium exhibit a maximum at intermediate heating rates, whereas Mg-containing alloys tend to expand more for higher heating rates.
\end{abstract}

Keywords: aluminium alloy foams; heating rate; powder processing

\section{Introduction}

The powder metallurgical route for the preparation of foamable metallic precursors is comprised of mixing metal powders and a blowing agent, densifying the powder blend (mostly in air) yielding a dense precursor, after which the foaming process is initiated by heating up to the melting range of the alloy in question. The resulting foam expansion and the final structure of the solidified foam are influenced by many conditions along this way such as alloy composition, type of compaction, compaction temperature or pressure, foaming temperature or holding time, and also by the heating rate up to the foaming temperature. The heating conditions are usually determined by the foaming set-up (e.g., furnace type, heat capacity of the system etc.) and can strongly vary.

The influence of the heating rate has been studied for the aluminium alloys 6061 [1] and AlSi6Cu4 [2]. Both studies concluded that there is a minimum heating rate needed to reach maximum expansion of foams. AlSi alloys with varying $\mathrm{Cu}$ and $\mathrm{Mg}$ additions were investigated at two heating rates. A slight improvement of expansion at higher heating rates was found [3]. Another study focused mainly on collapse mechanisms but also reported a dependence of the foaming behavior of AlSi7, AlSi9Cu3, and three more Al-Si-Cu alloys containing $\mathrm{Zn}$ additions on the heating rate [4]. However, no systematic study has been performed so far for heating rates covering a wide range of values.

\section{Experimental}

The alloys used in this study were AlSi7, AlCu13Mg4, AlSi6Cu4, and AlSi8Mg4 (all in wt \%). Powders of aluminium (Alpoco Ltd., Sutton Coldfield, UK, 99.7\% purity, D90 $=76 \mu \mathrm{m}$ ), silicon (Alchem Ltd., Burlington, ON, Canada, 99.5\% purity, D90 = $50 \mu \mathrm{m}$ ), copper (Chempur GmbH, Karlsruhe, Germany, 99.7\% purity, D90 = 53 $\mu \mathrm{m}$ ), prealloyed AlMg50 master alloy (Possehl Erzkontor $\mathrm{GmbH}$, Lübeck, Germany, D90 $=72 \mu \mathrm{m}$ ), and $\mathrm{TiH}_{2}$ serving as blowing agent (Chemetall $\mathrm{GmbH}$, Frankfurt am Main, Germany, $98.8 \%$ pure, D90 $=31 \mu \mathrm{m}$ ) were used to prepare foamable precursors. 
The $\mathrm{TiH}_{2}$ was heat-treated at $480{ }^{\circ} \mathrm{C}$ for $180 \mathrm{~min}$ in air in order to allow for the creation of a surface oxide layer and to shift the hydrogen release range to higher temperatures $[5,6]$. The powders were mixed in air for $30 \mathrm{~min}$. For compaction, $30 \mathrm{~g}$ of powder blend were subjected to $300 \mathrm{MPa}$ uniaxial pressure: first at $20^{\circ} \mathrm{C}$ for $10 \mathrm{~s}$ and then at $400{ }^{\circ} \mathrm{C}$ for $5 \mathrm{~min}$. The resulting cylindrical tablets of $36 \mathrm{~mm}$ diameter were eventually cut to samples of $(10 \times 10 \times 4) \mathrm{mm}^{3}$ size. The density of the compacted samples was $97.2 \pm 0.2 \%$ of their theoretical density.

Foaming was performed in air in an X-ray imaging system on a ceramic plate that could be resistively heated. The radioscopy set-up consists of a microfocus $\mathrm{X}$-ray source operated at $100 \mathrm{kV}$, and a $2240 \times 2368$ pixel flat panel detector [2], both from Hamamatsu, Japan. Analysis of the images allows for the calculation of the expansion profiles. The temperature used to control the heating power was measured by a thermocouple embedded directly in the plate beneath the sample. The set point temperatures were chosen individually for each alloy and were $80 \mathrm{~K}$ above the respective liquidus temperatures. After reaching the set point, the temperature was held for $240 \mathrm{~s}$ before heating was turned off and natural cooling started. Investigations were performed using controlled heating rates from $0.1 \mathrm{~K} / \mathrm{s}$ to $16 \mathrm{~K} / \mathrm{s}$. Additionally, heating with full power was carried out, which results in a non-linear heating profile, but averages to $18 \mathrm{~K} / \mathrm{s}$ and will hereinafter be referred to as $18 \mathrm{~K} / \mathrm{s}$. The given heating rate is controlled by the ceramic heating plate. The temperature difference for the unmelted precursor for all heating rates is smaller than $30 \mathrm{~K}$. A minimum of three foaming experiments were performed for each heating rate and each alloy.

\section{Results}

Figure 1 visualises the dependence of the projected area expansion of foams on the heating rate for four different alloys. Values for the highest expansion are presented along with expansion values measured during cooling. Selected X-ray radiographs are given to illustrate the structure of the foams in the moment of maximum expansion. For AlSi7 (Figure 1a), a maximum expansion level of around $440 \%$ area expansion can be observed for heating rates of $1 \mathrm{~K} / \mathrm{s}$ to $3 \mathrm{~K} / \mathrm{s}$. Higher $(>3 \mathrm{~K} / \mathrm{s}$ ) and lower $(<1 \mathrm{~K} / \mathrm{s})$ heating rates yield slightly lower maximum expansion values. The values for the end expansion are lower than the maximum values, indicating collapse. For most heating rates the end area expansion is only around $10 \%$ smaller than the maximum area expansion, except for heating rates of $5 \mathrm{~K} / \mathrm{s}$ to $10 \mathrm{~K} / \mathrm{s}$, where collapse values of up to $17 \%$ can be found. For higher rates, starting from $5 \mathrm{~K} / \mathrm{s}$, the end area expansion remains almost constant due to less collapse.

The curves for AlSi6Cu4 in Figure $1 \mathrm{~b}$ also exhibit a maximum at intermediate heating rates. The highest area expansion values $(\sim 375 \%)$ were reached by using heating rates of $5 \mathrm{~K} / \mathrm{s}$ and $7 \mathrm{~K} / \mathrm{s}$. Lower or higher heating rates yield lower maximum area expansion values. However, the highest end area expansions were reached for lower heating rates of $0.5 \mathrm{~K} / \mathrm{s}$ to $3 \mathrm{~K} / \mathrm{s}$ due to a lower collapse of only $\sim 10 \%$. In contrast, the collapse values increase continuously for heating rates higher than $3 \mathrm{~K} / \mathrm{s}$, whereby the highest collapse values $(\sim 28 \%)$ were found for the highest heating rates of $13 \mathrm{~K} / \mathrm{s}$ and $18 \mathrm{~K} / \mathrm{s}$. Thus, the lowest end area expansion was gained by using the highest heating rate $(18 \mathrm{~K} / \mathrm{s})$.

For $\mathrm{AlCu} 13 \mathrm{Mg} 4$, the highest heating rate $(18 \mathrm{~K} / \mathrm{s}$ ) gives the highest expansion (maximum: $375 \%$; end: $270 \%$ ), as shown in Figure 1c. Decreasing the heating rate leads to a continuous decrease of area expansion, revealing an almost monotonic dependence of expansion on heating rate. The collapse of foams also increases continuously with the rise of the heating rate: from $12 \%$ at $0.17 \mathrm{~K} / \mathrm{s}$ to more than $35 \%$ at $16 \mathrm{~K} / \mathrm{s}$.

Contrary to the results in the previous cases, the curve for AlSi8Mg4, depicted in Figure 1d, does not assume its minimum at the lowest heating rate, but rather a local minimum at intermediate heating rates at $2-2.5 \mathrm{~K} / \mathrm{s}$ is observed. This unexpected behavior was confirmed in 10 individual experiments. Nevertheless, the curves of maximum and end area expansion show an increase up to $0.5 \mathrm{~K} / \mathrm{s}$, a decrease up to $2 \mathrm{~K} / \mathrm{s}$, and a re-increase up to $16 \mathrm{~K} / \mathrm{s}$. For heating rates from $2 \mathrm{~K} / \mathrm{s}$ to $4 \mathrm{~K} / \mathrm{s}$ the maximum area expansion markedly increases from $143 \%$ to $307 \%$, respectively. Similarly high is the difference in the end area expansion which is increased by $137 \%$, whereas the magnitude of 
collapse remains roughly constant $(\sim 13 \%)$. A further increase of the heating rate leads to slightly larger expansion values until the highest maximum of $378 \%$ at $16 \mathrm{~K} / \mathrm{s}$ is reached, associated with a stronger collapse $(\sim 20 \%)$.
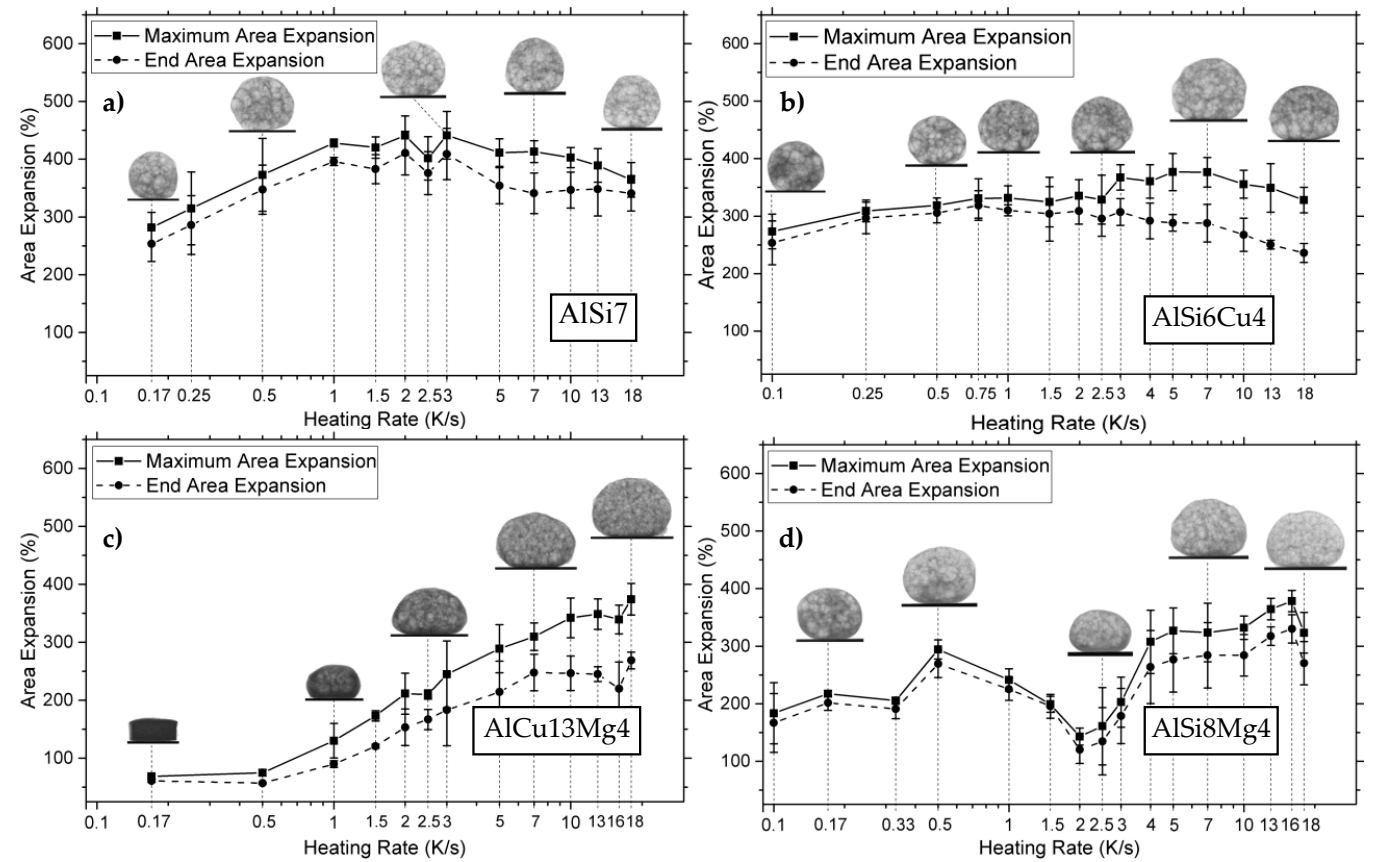

Figure 1. Maximum area expansion and end area expansion (measured during cooling at $\sim 300{ }^{\circ} \mathrm{C}$ ) as a function of the heating rate (logarithmic scale) applied to precursors of the alloys (a) AlSi7, (b) AlSi6Cu4, (c) AlCu13Mg4, and (d) AlSi8Mg4. Averages over all experiments carried out on a particular alloy are given. X-ray radioscopic images for one representative sample at the state of maximum expansion for the indicated heating rates are also displayed.

\section{Discussion}

All four alloys exhibit poor foam expansion at low heating rates. This behavior is probably caused by the long exposure of the sample to temperatures in the range of the decomposition range of the blowing agent (in AlSi11 precursor at $0.67 \mathrm{~K} / \mathrm{s}$ : Onset $531^{\circ} \mathrm{C}$, peak $585^{\circ} \mathrm{C}$ [7]) and gas losses before the alloy starts to melt and foaming occurs. Especially for Mg-free alloys, it was found that the weak solid metal matrix starts cracking at around $550{ }^{\circ} \mathrm{C}$ (Figure 2), which allows for the loss of hydrogen either through open fissures or by diffusion to the outside through thinner material layers. Another reason for poor expansion is the growing outer oxide skin. This effect has also been reported for the foaming of alloy AlSi7 in air [8]. When foams are heated slowly in air, their surface oxide layer will grow-starting already in the solid state [9] and increasingly higher forces are required to stretch or tear them [10], which is necessary to expand the foam [11]. This mechanism is effective even if new surface areas are created during expansion through tearing of old surface regions as those will oxidize immediately in the presence of air and at high temperatures. In particular, the alloy $\mathrm{AlCu} 13 \mathrm{Mg} 4$ represents this trend as $\mathrm{Mg}$ is known to increase oxidation markedly [12], thus hindering expansion even more, as it can be seen in Figure 1c at slow heating rates. This effect was also found for other Mg-containing alloys [13]. As Mg-free alloys already show pronounced expansions at low heating rates-compare Figure $1 \mathrm{a}-\mathrm{d}$ for $<0.4 \mathrm{~K} / \mathrm{s}$ - this supports the theory of a hindered expansion due to a growing oxide layer. Untreated as well as heat-treated $\mathrm{TiH}_{2}$ powders release slightly more gas when heated at $40 \mathrm{~K} / \mathrm{min}$ in comparison to heating at $10 \mathrm{~K} / \mathrm{min}$ [14]. Assuming that powder particles embedded in a compacted precursor show the same behavior provides another explanation for the poor expansion at low heating rates. 
Faster heating rates $(>3 \mathrm{~K} / \mathrm{s}$ ) were found to lead to lower end expansions and strong collapse for Mg-free alloys. This may be a product of the stabilization mechanisms of PM foams as suggested previously [15]. A stabilising oxide network, although able to withstand a certain strain, could be fragmented during foaming at high heating rates by higher hydrodynamic forces. This would lead to more drainage, coalescence, and thus collapse. Another phenomenon was observed at the heating rate transition from $2.5 \mathrm{~K} / \mathrm{s}$ to $3 \mathrm{~K} / \mathrm{s}$ for AlSi6Cu4. Aluminium alloy protrusions consisting of the lowest melting eutectic are pushed out on the sample surface at the beginning of expansion at $\sim 500{ }^{\circ} \mathrm{C}$. They are reabsorbed before the main expansion starts for heating rates of $2.5 \mathrm{~K} / \mathrm{s}$ or less, whereas they remain on the surface when heating with $3 \mathrm{~K} / \mathrm{s}$ and higher rates. The ternary eutectic consists of $68.1 \mathrm{wt} \% \mathrm{Al}, 26.6 \mathrm{wt} \% \mathrm{Cu}$, and $5.3 \mathrm{wt} \% \mathrm{Si}$ and melts at $524{ }^{\circ} \mathrm{C}$ [16]. This implies that near-surface areas, from where the melt originates, possesses a different phase composition-especially with less $\mathrm{Cu}$-than the inner volume of the foam when heated at $3 \mathrm{~K} / \mathrm{s}$ or faster. This could not only alter the expansion behavior, but also and even more pronouncedly alter the collapse behavior since near-surface areas are concerned.

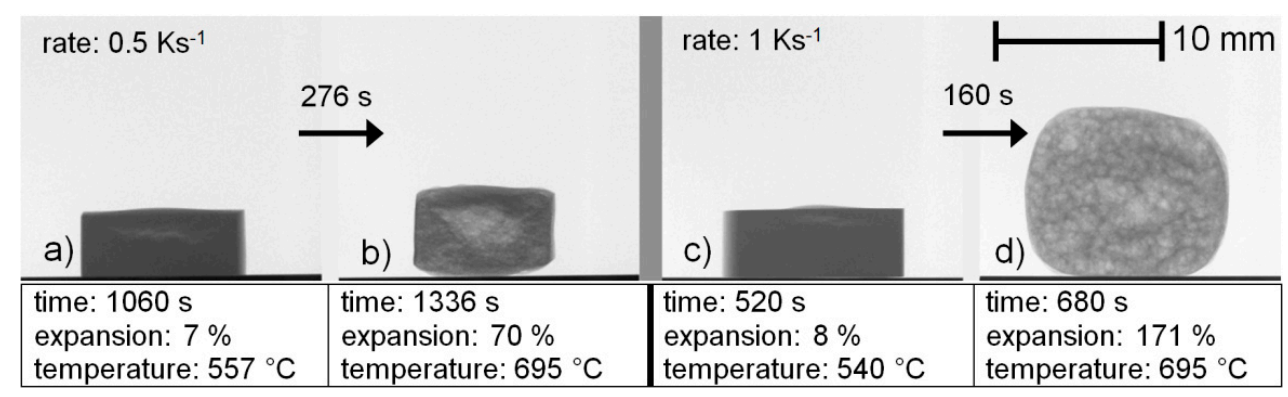

Figure 2. X-ray radiograms of foams after the first visible crack has been detected $(\mathbf{a}, \mathbf{c})$ and at the end of the heating ramp after $695^{\circ} \mathrm{C}$ has been reached $(\mathbf{b}, \mathbf{d})$ at heating rates of $0.5 \mathrm{~K} / \mathrm{s}$ (left) and $1 \mathrm{~K} / \mathrm{s}$ (right).

For alloys containing $\mathrm{Mg}$, see Figure $1 \mathrm{c}$, d, fast heating rates between $>4 \mathrm{~K} / \mathrm{s}$ are found to produce higher foam expansions than slow heating rates. Heating rates below $4 \mathrm{~K} / \mathrm{s}$ indeed give rise to a small collapse, but also to very dense areas with incompletely expanded material at the bottom. The expansion behavior of AlSi8Mg4 does not increase monotonically with heating rate but shows a local minimum around $2 \mathrm{~K} / \mathrm{s}$, see Figure $1 \mathrm{~d}$. Samples foamed at such heating rates exhibited dense, hardly expanded alloy already at the beginning of the expansion process. Increasing the heating rate from 0.1 to $0.5 \mathrm{~K} / \mathrm{s}$ or 4 to $16 \mathrm{~K} / \mathrm{s}$ improves expansion due to the decrease of negative effects-e.g., premature decomposition of $\mathrm{TiH}_{2}$-as explained earlier. For heating rates from 0.5 to $2 \mathrm{~K} / \mathrm{s}$, it seems that such negative effects become more prominent and cannot be compensated by positive effects such as improved sintering between particles, which would prevent gas losses, possibly aided by the formation of $\mathrm{MgAl}_{2} \mathrm{O}_{4}$ [17]. Beyond 2 to $4 \mathrm{~K} / \mathrm{s}$, a certain threshold is exceeded, above which gas losses are reduced again and foam expansion is improved quickly up to a constant rise of expansion for 0.1 to $0.5 \mathrm{~K} / \mathrm{s}$ or 4 to $16 \mathrm{~K} / \mathrm{s}$.

\section{Conclusions}

The relationship between the rate at which a foamable precursor is heated to the foaming temperature and the resulting foam expansion was investigated for four different aluminium alloys:

- All four alloys investigated exhibit a pronounced and non-linear dependence of expansion values on the heating rate.

- The collapse increases for all alloys when the heating rate exceeds approximately $3 \mathrm{~K} / \mathrm{s}$.

- Low heating rates lead to low expansions.

- High heating rates $(<4 \mathrm{~K} / \mathrm{s})$ improve expansion only in Mg-containing alloys. 
Author Contributions: Francisco Garcia-Moreno and John Banhart conceived and designed the experiments; Beate Pfretzschner performed the experiments and analyzed the data; Tillmann R. Neu wrote the paper.

Conflicts of Interest: The authors declare no conflict of interest.

\section{References}

1. Duarte, I.; Banhart, J. A study of aluminium foam formation-Kinetics and microstructure. Acta Mater. 2000, 48, 2349-2362. [CrossRef]

2. Garcia-Moreno, F.; Fromme, M.; Banhart, J. Real-time X-ray Radioscopy on Metallic Foams Using a Compact Micro-Focus Source. Adv. Eng. Mater. 2004, 6, 416-420. [CrossRef]

3. Helwig, H.M.; Garcia-Moreno, F.; Banhart, J. A study of $\mathrm{Mg}$ and $\mathrm{Cu}$ additions on the foaming behaviour of Al-Si alloys. J. Mater. Sci. 2011, 46, 5227-5236. [CrossRef]

4. Lehmhus, D. Dynamic collapse mechanisms in metal foam expansion. Adv. Eng. Mater. 2010, 12, 465-471. [CrossRef]

5. Jiménez, C.; Garcia-Moreno, F.; Pfretzschner, B.; Klaus, M.; Wollgarten, M.; Zizak, I.; Schumacher, G.; Tovar, M.; Banhart, J. Decomposition of TiH2 studied in situ by synchrotron X-ray and neutron diffraction. Acta Mater. 2011, 59, 6318-6330. [CrossRef]

6. Matijasevic, B.; Banhart, J. Improvement of aluminium foam technology by tailoring of blowing agent. Scr. Mater. 2006, 54, 503-508. [CrossRef]

7. Jiménez, C.; Garcia-Moreno, F.; Pfretzschner, B.; Kamm, P.H.; Neu, T.R.; Klaus, M.; Genzel, C.; Hilger, A.; Manke, I.; Banhart, J. Metal foaming studied in situ by energy dispersive X-ray diffraction of synchrotron radiation, X-ray radioscopy, and optical expandometry. Adv. Eng. Mater. 2013, 15, 141-148. [CrossRef]

8. Weigand, P. Untersuchung Der Einflußfaktoren Auf Die Pulvermetallurgische Herstellung Von Aluminiumschäumen; Verl. MIT: Bremen, Germany, 1999.

9. Field, D.J.; Scamans, G.M.; Butler, E.P. The high temperature oxidation of Al-4.2 Wt Pct Mg alloy. Metall. Trans. A 1987, 18, 463-472.

10. Kahl, W.; Fromm, E. Examination of the Strength of Oxide Skins on Aluminum Alloy Melts. Metall. Trans. $B$ 1985, 16, 47-51. [CrossRef]

11. Dudka, A.; García-Moreno, F.; Wanderka, N.; Banhart, J. Structure and distribution of oxides in aluminium foam. Acta Mater. 2008, 56, 3990-4001. [CrossRef]

12. Drouzy, M.; Mascré, C. The oxidation of liquid non-ferrous metals in air or oxygen. Int. Mater. Rev. 1969, 14, 25-46. [CrossRef]

13. Simančík, F.; Behulová, K.; Borš, L. Effect of ambient atmosphere on the foam expansion. In Cellular Metals and Metal Foaming Technology; Banhart, J., Ashby, M., Fleck, N., Eds.; MIT Publishing: Bremen, Germany, 2001; pp. 89-92.

14. Jiménez, C. Characterization and Modification of Powders Used to Make Aluminium-Based Metal Foams. Ph.D. Thesis, Technische Universität, Berlin, Germany, 2010.

15. Körner, C.; Arnold, M.; Singer, R.F. Metal foam stabilization by oxide network particles. Mater. Sci. Eng. A 2005, 396, 28-40. [CrossRef]

16. Lukas, H.L.; Lebrun, N. Aluminium-Copper-Silicon. Landolt-Börnstein Group IV Phys. Chem. 2003, 11, 135-147.

17. Guo, Z.Q.; Ma, D.H.; Yuan, X.G.; Dong, X. Effect of Mg Addition on the Foaming Behaviour of AlSi7 Based Alloy Prepared by Powder Metallurgy Method. Rare Met. Mater. Eng. 2016, 45, 3068-3073.

(C) 2017 by the authors. Licensee MDPI, Basel, Switzerland. This article is an open access article distributed under the terms and conditions of the Creative Commons Attribution (CC BY) license (http://creativecommons.org/licenses/by/4.0/). 